\title{
Perch exposure and predation risk: a comparative study in passerines
}

\author{
Diana P. Campos • Laith A. Bander • Aliz Raksi • \\ Daniel T. Blumstein
}

Received: 8 December 2008 /Revised: 13 April 2009/Accepted: 16 June 2009 /Published online: 22 July 2009

(C) The Author(s) 2009. This article is published with open access at Springerlink.com

\begin{abstract}
Singing birds optimize signal transmission by perching in exposed locations. However, conspicuous singing may be risky, and previous research has found that individuals trade off singing performance with song perch exposure. We studied the relationship between predation risk (degree of concealment, height in tree or shrub, and distance to the forest edge) and time allocated to singing and vigilance in a group of 13 passerine species living in an East African savanna. Concealed birds sang more and were less vigilant. Vigilance increased as distance to the forested edge increased, but distance had no effect on time allocated to singing. Body size was significantly correlated with vigilance but not singing; larger passerines were more sensitive to both relative concealment and the distance to the forest edge, while song was influenced by neither of these factors. Perch height had no effect on either behavior. Our results suggest that birds modify vigilance and, to some extent, singing behavior to minimize their exposure to predators.
\end{abstract}

Keywords Birdsong · Perch exposure · Predation risk . Singing behavior

Communicated by P. Heeb

D. P. Campos · L. A. Bander · A. Raksi • D. T. Blumstein $(\bowtie)$

Department of Ecology and Evolutionary Biology,

University of California,

621 Young Drive South,

Los Angeles, CA 90095-1606, USA

e-mail: marmots@ucla.edu

\section{Introduction}

Birds sing to increase their fitness (Catchpole and Slater 1995; Gil and Gahr 2002), but such benefits do not come without costs. Singing takes time and uses energy (Gil and Gahr 2002). Studies on European robins (Erithacus rubecula) demonstrate a significant tradeoff between time allocated to singing and feeding: individuals who devoted more time to singing often suffered the greatest energy storage losses (Thomas et al. 2003), and comparative studies also show that species with higher metabolic rates have decreased song outputs (Read and Weary 1992). Singing may also increase exposure to predators (Ward and Slater 2005).

Singing birds can maximize their song transmission if they sing in exposed places (Ward and Slater 2005). For instance, male Golden-winged warblers (Vermivora chrysoptera) predominantly select high song perches to enhance their ability to perform visual and vocal displays to best attract mates (Rossell 2001). While singing from high, exposed perch sites optimizes signal transmission, it leaves the signaler vulnerable to attack from aerial predators (Gil and Gahr 2002) because singers are more easily detectable to predators (Møller et al. 2005; Ward and Slater 2005). Audio playback studies with crested tits (Parus cristatusKrams 2001a) and blue petrels (Halobaena caeruleaMougeot and Bretagnolle 2000) demonstrated that singing attracts predators.

We see responses to the risk created by conspicuous acoustic displays. For instance, predatory parasitoids localize crickets (Teleogryllus oceanicus) from their stridulatory song (Zuk and Kolluru 1998) creating a strong selective pressure against singing (Zuk et al. 2006). Birds also modify their singing behavior as a result of predation risk (Krams 2001b; Møller et al. 2005; Ward and Slater 
2005). For instance, northern cardinals (Cardinalis cardinalis) chose more concealed perches to reduce predation risk (Duncan and Bednekoff 2006).

We examined the relationship between bird singing behavior and song perch selection in a community of breeding male passerines in the East African savanna. This location contained a rich and diverse community of aerial predators (Bildstein et al. 2000). Previous studies that have examined the height at which birds perch in trees and the concealment provided by song perches have only been done in temperate forests (Duncan and Bednekoff 2006; Rossell 2001). While many studies have looked at conspicuousness and predation risk, few studies have utilized a multispecies approach to examine these factors (Garamszegi and Avilés 2005; Møller et al. 2005; Krams 2001b)

To see how predation risk is correlated with singing behavior, we evaluated the following predictions: (1) passerines perching relatively high in trees will allocate more time to vigilance and less to singing; (2) passerines in more concealed perches will allocate more time to singing and less to vigilance; (3) environmental factors associated with predation risk will be significantly correlated with time allocated to singing; and (4) the time allocation to singing and vigilance for larger bodies species will be less sensitive to changes in exposure than smaller species.

\section{Materials and methods}

Study area

We studied singing behavior from 12 to 30 October 2007, at three sites (River Camp: $0^{\circ} 17.975^{\prime} \mathrm{N} 36^{\circ} 54.359^{\prime} \mathrm{E}$; Mpala Research Center: $0^{\circ} 17.580^{\prime} \mathrm{N}, 36^{\circ} 54.015^{\prime} \mathrm{E}$; JR Rock: $0^{\circ} 17.831^{\prime} \mathrm{N}, 36^{\circ} 54.325^{\prime} \mathrm{E}$ ) in and around the Mpala Research Center, Laikipia District, Kenya. The area has high biodiversity and is home to over 300 species of birds, including 35 species of raptors (Lynch et al. 2005). The woody vegetation consists mainly of thorny trees and shrubs (see Young et al. 1995 for a description).

\section{Procedures}

We studied birds from 0600 (sunrise) to 1100 hours. To assess the proportion of time allocated to singing, we recorded 3-min focal samples of different species of birds perching in shrubs and trees using a microcassette recorder. During focal sampling, we noted the onset of the following behaviors: song (vocalizations with easily distinguishable tonal variation), calls (simple, tonal vocalizations with a short duration), vigilance (birds were perched with their heads up and their eyes open), and locomotion (flying, hopping, and walking). We also noted other behaviors such as foraging, preening, stretching wings, and sleeping. Focal samples were terminated when birds flew away or moved out of sight behind vegetation.

For each focal sample, we noted date, species, sex (when distinguishable), perch characteristics, and recorded information regarding biotic and abiotic environmental factors. In order to assess the bird's exposure, we modified a scoring system used by Duncan and Bednekoff (2006) to determine relative perch height (such that a bird positioned in the topmost tenth of the plant is rated 10 and one in the bottom tenth is rated 1 - Fig. 1) and visual exposure to observer $(0$ is bird completely visible on a perch that juts out and has no foliage on either side of the bird, 1 is foliage on one side of the bird, 2 and 3 are foliage surrounding the bird from two or three sides, respectively, and 4 is completely concealed, in which case the bird is surrounded by foliage from all sides). We measured the absolute height in shrubs and trees by extending an arm, visually rotating the vertical distance in a shrub or tree, then measuring this distance on the ground (Blumstein et al. 2004). Finally, we noted the distance the focal bird was from the forested edge. Distances were measured in paces and then converted to meters. Observers trained with this procedure until all measurements were consistent.

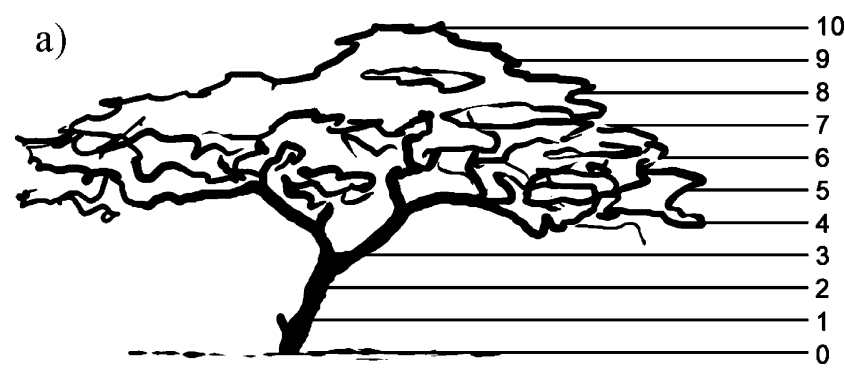

b)

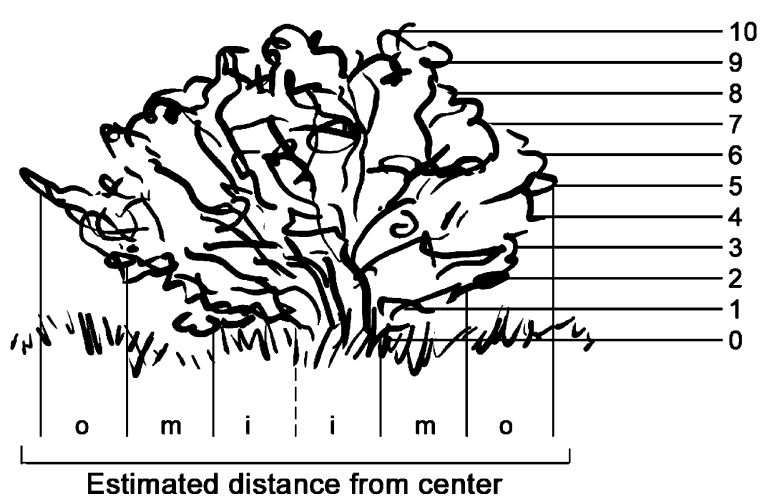

Fig. 1 Scoring system used to measure relative perch height in a tree or b shrub. Vegetation was visually divided into 10 horizontal layers such that 10 is the top, and 1 is the bottom tenth of the tree or shrub. Distance from center to perch was initially approximated as located in the inside $(i)$, middle $(m)$, or outer $(o)$ portion of the foliage to provide an instantaneous assessment prior to recording focal samples 
Table 1 Passerines studied

\begin{tabular}{llcc}
\hline Species & Latin name & Sample size $(n)$ & Midpoint size (cm) \\
\hline Baglafecht weaver & Ploceus baglafecht & 12 & 14.61 \\
Black-headed oriole & Oriolus larvatus rolleti & 11 & 20.96 \\
Common bulbul & Pycnonotus barbatus & 11 & 17.15 \\
Common drongo & Dicrurus adsimilis & 11 & 24.13 \\
Greater blue-eared starling & Lamprotornis chalybaeus & 15 & 23.50 \\
Gray-backed camaroptera & Camaroptera brachyura & 5 & 10.16 \\
Hildebrandt's starling & Lamprotornis hildebrandti & 10 & 19.69 \\
Red headed Weaver & Anaplectes rubriceps & 4 & 13.34 \\
Rufous chatterer & Turdoides rubiginosus & 4 & 19.69 \\
Slate colored boubou & Laniarius funebris & 10 & 19.37 \\
Superb starling & Lamprotornis superbus & 27 & 18.42 \\
Vitelline masked weaver & Ploceus velatus uluensis & 4 & 13.38 \\
White-browed sparrow weaver & Plocepasser mahali & 20 & 16.51 \\
\hline
\end{tabular}

Body sizes, converted from inches, from Zimmerman et al. (1999)
2004; Cibois 2003; Fuchs et al. 2004; Lovette and Rubenstein 2002; Sorenson and Payne 2001).

\section{Results}

Species explained no significant differences in our measured dependent variables (Tables 2 and 3 ). The height that birds perched had no significant effect on time allocated to singing (partial $\eta^{2}=-0.008, p=0.296$; Table 2) or vigilance (partial $\eta^{2}=0.018, p=0.121$; Table 3 ). Birds concealed in vegetation allocated a larger portion of their time to signing (partial $\eta^{2}=0.035, p=0.033$; Table 2) and less time to vigilance (partial $\eta^{2}=0.143, p<0.001$; Table 3 ). Additionally, birds that were further away from the forested edge

Table 2 The effect of exposure to predation risk on time allocated to singing after controlling for species-specific responses

\begin{tabular}{llcc}
\hline Independent variable & Beta & $p$ Value & Effect size \\
\hline Model $^{\mathrm{a}}$ & -0.006 & 0.481 & -0.002 \\
Species & & 0.417 & 0.088 \\
Perch height in tree $^{\mathrm{N}}$ & & 0.296 & 0.008 \\
Model $^{\mathrm{b}}$ & 0.021 & 0.239 & 0.024 \\
Species & & 0.308 & 0.098 \\
Concealment $_{\text {Model }}^{\mathrm{c}}$ & & 0.033 & 0.035 \\
Species & 0.0001 & 0.573 & -0.011 \\
Distance to forest edge & & 0.511 & 0.0800 \\
\end{tabular}

Beta values for continuous variables, $p$ value, and effect size (adjusted $R^{2}$ values for the model and partial $\eta^{2}$ values for independent variables) are provided

${ }^{\text {a }}$ Perch height in tree

${ }^{\mathrm{b}}$ Concealment

${ }^{\mathrm{c}}$ Distance to the forest edge this last analysis based on a phylogeny constructed using the following sources (Alström et al. 2006; Barker et al. 
Table 3 The effect of exposure to predation risk on time allocated to vigilance after controlling for species-specific responses

\begin{tabular}{lccc}
\hline Independent variable & Beta & $p$ Value & Effect size \\
\hline${ }^{\mathrm{a}}$ Model & & 0.098 & 0.050 \\
Species & & 0.151 & 0.118 \\
Perch height in tree & 0.016 & 0.121 & 0.018 \\
${ }^{\mathrm{b}}$ Model & & $<0.001$ & 0.171 \\
Species & & 0.146 & 0.119 \\
Concealment & -0.075 & $<0.001$ & 0.143 \\
${ }^{\mathrm{c}}$ Model & & 0.024 & 0.084 \\
Species & & 0.104 & 0.128 \\
Distance to forest edge & 0.002 & 0.008 & 0.053 \\
\hline
\end{tabular}

Beta values for continuous variables, $p$ value, and effect size (adjusted $R^{2}$ values for the model and partial $\eta^{2}$ values for independent variables) are provided

${ }^{a}$ Perch height in tree

${ }^{\mathrm{b}}$ Concealment

${ }^{\mathrm{c}}$ Distance to the forest edge

also allocated more time to vigilance (partial $\eta^{2}=0.053$, $p=0.008$; Table 3), but there was no significant effect on singing (partial $\eta^{2}=0.0002, p=0.882$, Table 2). Finally, body size explained substantial variation in risk taking for vigilance (Fig. 2a, c) but not for singing (Fig. 2b, d).
Results were essentially identical in the analyses calculated with phylogenetically independent contrasts (sensitivity to concealment for vigilance $R=0.759, B=0.027$, $p=0.0026$; sensitivity to concealment for song $R=0.002$, $B=0, p=0.995$; sensitivity to forest edge for vigilance $R=0.838, B=0.030, p=0.0003$; sensitivity to forest edge for song $R=0.439, B=-0.006, p=0.134$ ).

\section{Discussion}

We found no evidence that perching at a greater height influenced song behavior. Our finding corroborates a previous study that found that singing was not correlated with increased perch height (Götmark and Post 1996). Although we found no evidence that birds allocated less time to singing while perched at higher song posts, many species have been found to prefer high song posts despite an apparent increased predation risk (Krams 2001b). This indicates that individuals may be able to sing and scan for predators simultaneously. Thus, perching at a greater height may provide superior visibility of surroundings, effectively reducing the risk of predation (Møller et al. 2005; Krams 2001a, b; Götmark and Post 1996).

We found clear evidence of a relationship between perch concealment and singing behavior. Passerines sang
Fig. 2 The effect of body size on sensitivity to concealment (a, b) or sensitivity to distance from forest edge $(\mathbf{c}, \mathbf{d})$ while vigilant $(\mathbf{a}, \mathbf{c})$ or while singing $(\mathbf{b}, \mathbf{d})$. Partial-eta square values are for the effect of body size on sensitivity measures after controlling for nonsignificant variation (all $p$ values $>0.154$ ) explained by sample size
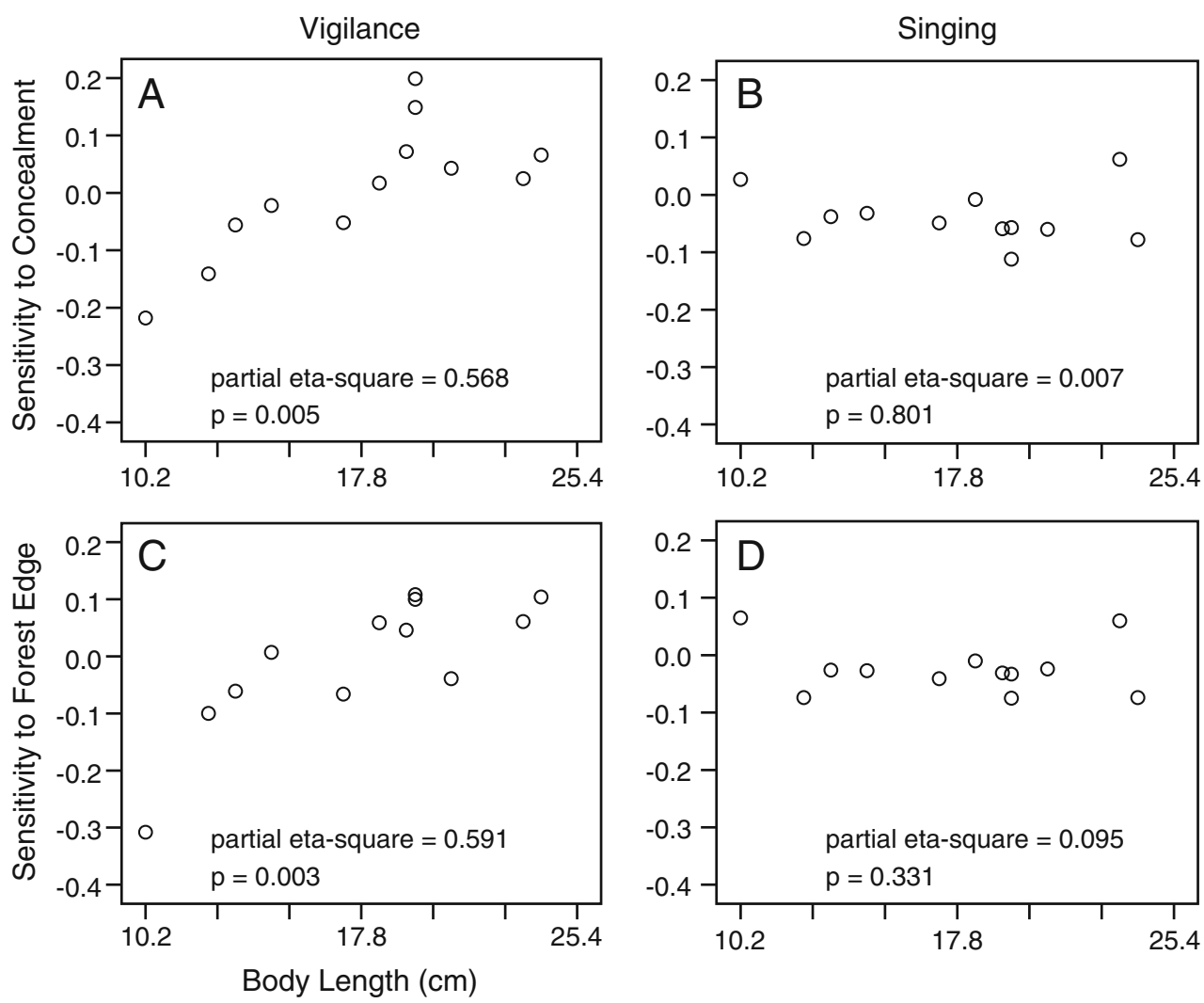
for a greater proportion of time and engaged in less vigilance when they were in more concealed perches. Our findings parallel recent studies that have shown birds that sing from more concealed perches are subject to lower predation risk (Duncan and Bednekoff 2006). Since predation by avian predators is the main cause of mortality in passerines (Møller et al. 2005), being less visible to avian predators and increasing vigilance are effective antipredation strategies. Our results, thus, provide further evidence that birds make a tradeoff between singing and anti-predator behavior.

Previous studies have found a positive association between distance to cover and time allocated to vigilance (Caraco et al. 1980; Elgar 1989). Our results parallel these findings since we found a significant relationship between distance from the forested edge and proportion of time allocated to vigilance. Specifically, passerines that were closer to the forest edge allocated less time to vigilance when perched. Studies on yellow-eyed juncos and willow tits showed that they increased vigilance as distance to forested edge increased (Caraco et al. 1980; Hogstad 1988), which may be attributed to an increased predation risk with distance to forested edge. This provides evidence for the idea that passerines make perch selections based on wariness as well as alter their behavior to best avoid predation.

We found that body size influenced the sensitivity to the concealment metric. Specifically, when more concealed, larger birds tended to allocate more time to vigilance than smaller birds. This may be due to large birds being inherently more conspicuous than smaller birds and, thus, more vulnerable to predation in the same microhabitat (Lima 1993). Our results imply that larger passerines may assess risk differently than smaller ones as large birds receive fewer anti-predatory benefits from the same amount of cover than smaller birds.

We also found that body size influenced the sensitivity to the exposure metric. Specifically, when farther from the forest edge, larger birds tended to allocate more time to vigilance than smaller birds. It has been shown that refuge is a valuable environmental asset to minimize predation risk (FérnandezJuricic et al. 2006). We, therefore, infer that larger birds assess risk differently than smaller birds because increased body mass decreases escape abilities (Witter et al. 1994; Nudds and Bryant 2000). Alternatively, larger-bodied birds may be more attractive to predators and, thus, are relatively more vulnerable. Based on the observed differences in song and vigilant behavior patterns, our results provide evidence that larger passerines tend to perceive a higher level of predation risk than smaller ones at similar levels of concealment and distance to forested edge.

Our study, along with previously mentioned studies, shows the strong correlation between distance to forested edge and avian behavior. Continued land use and habitat fragmentation vastly increases the amount of forested edge and the distance between patches of forest (Murcia 1995). Management strategies that consider the implications of forested edge on bird behavior could enhance the coexistence between wildlife and humans.

Acknowledgements We are extremely thankful to Director Margaret Kinnaird, Christopher Odhiambo, and the staff of Mpala who welcomed us and facilitated our work and Antony Eshwa, Mathew Nermon, and Lucretia Olson for help in the field and laboratory. We thank the Kenyan Ministry of Science and Technology for permission to work at MPALA and the UCLA Department of Ecology and Evolutionary Biology, the UCLA Office of Instructional Development, and the Lida Scott Brown Endowment for partial support. We thank two astute, anonymous reviewers for very constructive comments and Alex Kirschel for constructing the phylogeny that we used in comparative analyses.

Open Access This article is distributed under the terms of the Creative Commons Attribution Noncommercial License which permits any noncommercial use, distribution, and reproduction in any medium, provided the original author(s) and source are credited.

\section{References}

Alström P, Ericson GP, Olsson U, Sundberg P (2006) Phylogeny and classification of the avian superfamily Sylvioidea. Mol Phylo Evol 38:381-397. doi:10.1016/j.ympev.2005.05.015

Barker FK, Cibois A, Schikler P, Feinstein J, Cracraft J (2004) Phylogeny and diversification of the largest avian radiation. Proc Natl Acad Sci USA 101:11040-11045. doi:10.1073/pnas. 0401892101

Bildstein KL, Zalles J, Ottinger J, McCarty K (2000) Conservation biology of the world's migratory raptors: status and strategies. In: Chacellor RD, Meyburg BU (eds) Raptors at Risk Hancock House Publishers. Blaine, WA, pp 573-590

Blumstein DT, Daniel JC, Evans CS (2006). JWatcher 1.0. http:// www.jwatcher.ucla.edu.

Blumstein DT, Fernández-Juricic E, LeDee O, Larsen E, RodriguezPrieto I, Zugmeyer C (2004) Avian risk assessment: effects of perching height and detectability. Ethology 110:273-285. doi:10.1111/j.1439-0310.2004.00970.x

Caraco T, Martindale S, Pulliam HR (1980) Avian time budgets and distance to cover. Auk 97:872-875

Catchpole CK, Slater PBJ (1995) Bird song: biological themes and variations. Cambridge University Press, Cambridge

Cibois A (2003) Mitochondrial DNA phylogeny of babblers. Auk 120:3554. doi:10.1642/0004-8038(2003)120[0035:MDPOBT]2.0.CO;2

Duncan WJ, Bednekoff PA (2006) Singing in the shade: song and song posts of northern cardinals near nesting Cooper Hawks. Can J Zool 84:916-919. doi:10.1139/Z06-065

Elgar MA (1989) Predator vigilance and group size in mammals and birds: a critical review of the empirical evidence. Biol Rev Camb Philos Soc 64:13-34. doi:10.1111/j.1469-185X.1989.tb00636.x

Férnandez-Juricic E, Blumstein DT, Abrica G, Manriquez L, Bandy AL, Adams R, Daneshrad M, Rodriguez-Prieto I (2006) Relationships of anti-predator escape and post-escape responses with body mass and morphology: a comparative avian study. Evol Ecol Res 8:731-752

Fuchs J, Bowie RCK, Fjeldsá J, Pasquet E (2004) Phylogenetic relationships of the African bush-shrikes and helmet-shrikes 
(Passeriformes: Malaconotidae). Mol Phylo Evol 33:428-439. doi:10.1016/j.ympev.2004.06.014

Garamszegi LZ, Avilés JM (2005) Brood parasitism by brown-headed cowbirds and the expression of sexual characters in their hosts. Behav Ecol 143:167-177

Gil D, Gahr M (2002) The honesty of bird song: multiple constraints for multiple traits. Trends Ecol Evol 17:133-141. doi:10.1016/ S0169-5347(02)02410-2

Götmark F, Post O (1996) Prey selection by sparrowhawks, Accipiter nisus: Relative predation risk for breeding passerine birds in relation to their size, ecology and behaviour. Philos Trans Biol Sci 351:1559-1577. doi:10.1098/rstb.1996.0141

Hogstad O (1988) Social rank and antipredator behaviour of willow tits Parus montanus in winter flocks. Ibis 130:45-56. doi:10.1111/j.1474-919X.1988.tb00954.x

Krams I (2001a) Communication in crested tits and the risk of predation. Anim Behav 61:1065-1068. doi:10.1006/anbe. 2001.1702

Krams I (2001b) Perch selection by singing chaffinches: a better view of surroundings and the risk of predation. Behav Ecol 12:295300. doi:10.1093/beheco/12.3.295

Lima SL (1993) Ecological and evolutionary perspectives on escape from predatory attack: A survey of North American birds. Wilson Bull 105:1-47

Lovette IJ, Rubenstein DR (2002) A comprehensive molecular phylogeny of the starlings (Aves: Sturnidae) and mockingbirds (Aves: Mimidae): Congruent mtDNA and nuclear trees for a cosmopolitan avian radiation. Mol Phylo Evol 44:1031-1056. doi:10.1016/j.ympev.2007.03.017

Lynch JF, Tait C, Niven DK, Talbot SA (2005) Check-list of the birds of Mpala Research Centre and Mpala Ranch, Laikipia District, Kenya http://www.mpala.org/researchetr/environment/birdlist.php.

Møller AP, Nielsen JT, Garamszegi LZ (2005) Song post exposure, song features and predation risk. Behav Ecol 17:155-163. doi:10.1093/beheco/arj010

Mougeot F, Bretagnolle F (2000) Predation as a cost of sexual communication in nocturnal seabirds: an experimental approach using acoustic signals. Anim Behav 60:647-656. doi:10.1006/ anbe. 2000.1491
Murcia C (1995) Edge effects in fragmented forests: Implications for conservation. Trends Ecol Evol 10:58-62. doi:10.1016/S01695347(00)88977-6

Nudds RL, Bryant DM (2000) The energetic cost of short flights in birds. J Exp Biol 203:1561-1572

Read AF, Weary DM (1992) The evolution of bird song: comparative analyses. Philos Trans Biol Sci 338:165-187. doi:10.1098/ rstb.1992.0137

Rossell CR Jr (2001) Song perch characteristics of the golden-wing warblers in wetland. Wilson Bull 113:246-248. doi:10.1676/ 0043-5643(2001)113[0246:SPCOGW]2.0.CO;2

Sorenson MD, Payne RB (2001) A single ancient origin of brood parasitism in African finches: Implications for host-parasite coevolution. Evolution 55:2550-2567

SPSS (2005) SPSS Release 14.0. SPSS, Chicago

Thomas RJ, Cuthill IC, Goldsmith AR, Cosgrove DF, Lidgate HC, Proctor SLB (2003) The trade-off between singing and mass gain in a daytime-singing bird, the European robin. Behaviour 140:387-404. doi:10.1163/156853903321826693

Ward S, Slater PJB (2005) Raised thermoregulatory costs at exposed song posts increase the energetic cost of singing for willow warblers. Phylloscopus trochilus. J Avian Biol 36:280-286. doi:10.1111/j.0908-8857.2005.03379.x

Witter MS, Cuthill IC, Bonser RHC (1994) Experimental investigations of mass-dependent predation risk in the European starling, Sturnus vulgaris. Anim Behav 48:201-222. doi:10.1006/anbe. 1994.1227

Young TP, Patridge N, Macrae A (1995) Long-term glades in acacia bushland and their edge effects in Laikipia, Kenya. Ecol Appl 5:97-108. doi:10.2307/1942055

Zimmerman DA, Turner DA, Pearson DJ (1999) Birds of Kenya and Northern Tanzania. Princeton University Press, Princeton

Zuk M, Kolluru GR (1998) Exploitation of sexual signals by predators and parasitoids. Q Rev Biol 73:415-438. doi:10.1086/ 420412

Zuk M, Rotenberry JT, Tinghitella RM (2006) Silent night: adaptive disappearance of a sexual signal in a parasitized population of field crickets. Biol Lett 2:521-524. doi:10.1098/ rsb1.2006.0539 